\title{
SOLUBILITY ENHANCEMENT OF CELECOXIB BY SOLID DISPERSION TECHNIQUE AND INCORPORATION INTO TOPICAL GEL
}

\author{
AMRIN SHAIKH, PRASHANT BHIDE, REESHWA NACHINOLKAR* \\ Department of Pharmaceutics, Goa College of Pharmacy, Panaji, Goa, India. Email: resh2593@gmail.com
}

Received: 17 September 2018, Revised and Accepted: 26 October 2018

\begin{abstract}
Objective: The aim of the present investigation was to design gels for the topical delivery of celecoxib and evaluate with an aim to increase its penetration through the skin and thereby its flux.

Method: The solubility of celecoxib is shown to be increased by preparing solid dispersions (SDs) using carriers such as mannitol, polyvinylpyrrolidone (PVP-K30), polyethylene glycol (PEG) 6000 and urea by solvent evaporation, fusion, and coevaporation methods. In vitro release profile of all SD was comparatively evaluated and studied against the pure drug. The prepared SD was subjected for percent practical yield, drug content, infrared spectroscopy, differential scanning calorimetry analysis, X-ray diffraction studies, and scanning electron microscopy (SEM) imaging. The celecoxib gel was prepared using hydroxypropyl methyl cellulose (HPMC) and Carbopol containing a permeation enhancer dimethyl sulfoxide (DMSO) at different proportions and evaluated for drug content, $\mathrm{pH}$, viscosity, spreadability, extrudability, stability, and in vitro drug release.
\end{abstract}

Results: Faster dissolution rate was exhibited by SD containing 1:5 ratio of celecoxib: PVP K-30 prepared by coevaporation method. In vitro drug release of celecoxib, gels revealed that formulation with HPMC has higher drug release as compared to Carbopol.

Conclusion: The increase in dissolution rate for SD is observed in the following order of PVP K-30> urea>mannitol>PEG 6000. The CPD5 gel containing a SD CP5 and 20\% DMSO showed the best in vitro release $74.13 \%$ at the end of $6 \mathrm{~h}$.

Keywords: Celecoxib, Solid dispersion, Solid dispersion incorporated gels, Hydroxypropyl methyl cellulose K4M, In vitro drug release.

(C) 2019 The Authors. Published by Innovare Academic Sciences Pvt Ltd. This is an open access article under the CC BY license (http://creativecommons. org/licenses/by/4. 0/) DOI: http://dx.doi.org/10.22159/ajpcr.2019.v12i2.29784

\section{INTRODUCTION}

Solubility is an important physicochemical factor which affects the absorption of drugs and, in turn, affects its therapeutic effectiveness. According to the biopharmaceutics classification system, drugs with low aqueous solubility and high membrane permeability are categorized as Class II drugs. Solid dispersion (SD) method involves dispersion of the drug in the extremely fine state in an inert water-soluble carrier in the solid state [1].

The USP defines gels as semisolid systems consisting of either suspension made up of small inorganic particles or large organic molecules interpenetrated by liquid. Some important polymers used to prepare pharmaceutical gels include natural gums such as tragacanth, pectin, carrageenan, agar, and alginic acid, and synthetic and semisynthetic materials such as methyl cellulose, hydroxyethylcellulose, and carboxymethyl cellulose [1].

Rheumatoid arthritis (RA) is an autoimmune disease causing chronic inflammation of the joints. RA shows inflammation of the tissue around the joints and inflammatory arthritis as characteristic features. The disease can also cause inflammation and injury in other organs in the body [3]. Aspirin and cortisone (corticosteroids) are first-line drugs, used to reduce pain and inflammation. The slow-acting second-line drugs, such as methotrexate (Rheumatrex and trexall), and hydroxychloroquine (plaquenil), promote disease remission, and prevent joint destruction. Celecoxib (Celebrex), a newer nonsteroidal anti-inflammatory drug showing selective COX-2 inhibitor action, offers anti-inflammatory effects with less risk of stomach irritation and bleeding risk [2].

Celecoxib shows poor aqueous solubility $(3 \mu \mathrm{g} / \mathrm{ml})$ which is major drawback. Incomplete absorption of celecoxib from the gastrointestinal tract results in poor water solubility, in turn, showing low bioavailability [2]. Celecoxib has a very low oral bioavailability of just about $40 \%$. It is reported that oral formulations of celecoxib can cause gastric mucosal damage, which may result in ulceration and bleeding, stomatitis, duodenal perforations, blood clots leading to fatal heart attacks, and strokes. These side effects are rare but very fatal.

Therefore, there is a need to develop topical dosage forms of celecoxib to minimize the gastrointestinal side effects of oral celecoxib and to provide relatively consistent drug levels at the application site for prolonged periods. This study aims to apply the SD method using mannitol, polyvinylpyrrolidone (PVP-K30), polyethylene glycol (PEG) 6000 , and urea as carriers, and study the dissolution behavior as well as the increase in aqueous solubility of celecoxib thereby proving the efficiency of the SD method [4]

The present study aims to study the release rate of topically administered celecoxib with a novel approach using SD incorporated gels in the presence and absence of permeability enhancer.

\section{MATERIALS AND METHODS}

\section{Materials}

Celecoxib was obtained from Unichem Laboratories Ltd., polyvinylpyrrolidone K-30 from Geno Pharmaceuticals, PEG 6000, and sodium lauryl sulfate from HiMedia Laboratories Pvt. Ltd., mannitol from Loba Chemie Pvt., Ltd., and urea from Molychem as gift sample. All reagents used were of analytical grade.

\section{Methodology}

Preparation of calibration curve of celecoxib in methanol, distilled water with 1\%SLS, and phosphate buffer pH 7.4

A standard stock solution containing $100 \mu \mathrm{g} / \mathrm{ml}$ was prepared in methanol. From the working standard solution, concentrations of 
2-20 $\mu \mathrm{g} / \mathrm{ml}$ were prepared by dilution with methanol, distilled water with $1 \%$ SLS, and phosphate buffer $\mathrm{pH}$ 7.4. The calibration curve for celecoxib was plotted on concentration versus absorbance at $254 \mathrm{~nm}$ on PerkinElmer Lambda 25 UV/VIS Spectrometer. Regression analysis was performed, and the concentration of celecoxib was determined [2].

Compatibility studies between the drug and excipients by infrared (IR) spectroscopy:

The IR absorption spectrum was obtained by preparing a simple physical mixture of the drug and the carrier/excipient [3,4]. The mixture was then placed on the stage of the instrument and scanned by the passage of an IR beam through it. The spectra were scanned over a frequency range $4000-600 \mathrm{~cm}^{-1}$.

Preparation of SDs:

SDs were prepared by various polymers and different methods as shown in Table 1.

\section{Solvent evaporation method}

The required amount of celecoxib and carrier in 1:1, 1:3, and 1:5 ratios was dissolved in a sufficient volume of methanol with continuous stirring. The solvent from solution was removed at $45^{\circ} \mathrm{C}$ by continuous stirring to obtain a dry mass. The dried mass was pulverized, passed through 44 mesh sieve and stored in a desiccator $[5,6]$.

\section{Fusion method}

Accurately weighed the amount of carrier was melted in a porcelain dish at $80-85^{\circ} \mathrm{C}$ and to this calculated amount of celecoxib was added with thorough mixing for 1-2 min followed by quick cooling. The dried mass was pulverized, passed through 44 mesh sieve and stored in a desiccator $[5,6]$.

\section{Coevaporation method}

Celecoxib is dissolved in methanol and carrier in aqueous media. Subsequently, the organic drug solution is slowly added to the aqueous carrier solution followed by stirring at 300 rpm using a magnetic stirrer at $37^{\circ} \mathrm{C}$ for $24 \mathrm{~h}$. Resultant $\mathrm{SD}$ is passed through a 120 mesh sieve $[5,7,8]$.

The prepared SDs were evaluated for its physical appearance, percent practical yield, and drug content analysis.

\section{In vitro dissolution study}

The release of the drug in vitro was determined by estimating the dissolution profile. Regression analysis was performed and celecoxib concentration was determined [9].

\section{Aqueous solubility studies}

The aqueous solubility analysis was performed on the SDs by adding an excess amount of the SD, that is, $50 \mathrm{mg}$ to $10 \mathrm{ml}$ of distilled water in a stoppered conical flask and shaken using a rotary shaker at room temperature for $24 \mathrm{~h}$. An aliquot was withdrawn and was filtered through Whatman filter paper no.40. The filtrate was analyzed for drug concentration by UV [9].

Differential scanning colorimetry (DSC) analysis

DSC studies were carried out in which samples were examined using a Mettler Toledo (DSC 823) instrument. 3-4 mg of samples was weighed into an aluminum pan and sealed with a lid having a pinhole in the center. Sealed pan-lid is then loaded on DSC instrument and heated from $25^{\circ} \mathrm{C}$ to $200^{\circ} \mathrm{C}$ at a heating rate of $10^{\circ} \mathrm{C} / \mathrm{min}$. Nitrogen was used as the purge gas for the instrument [7].

\section{Scanning electron microscopy (SEM) studies}

SEM studies were performed using TM3000 tabletop microscope. The prepared slides were loaded one by one into this instrument which gave the SEM images of the sample at the desired magnification [7].

$X$-ray diffraction (XRD) studies

The SDs were subjected to XRD studies to study any changes in the solid state of the drug. The samples of SD were analyzed using the Bruker D8 Advance powder XRD instrument. The samples were

Table 1: Formulation ingredients, preparation method of celecoxib SDs

\begin{tabular}{|c|c|c|c|}
\hline Batch code & Composition & Method & Ratio (Drug: Carrier) \\
\hline SP1 & Celecoxib+PVP K-30 & Solvent Evaporation & $1: 1$ \\
\hline SP3 & Celecoxib+PVP K-30 & Solvent Evaporation & $1: 3$ \\
\hline SP5 & Celecoxib+PVP K-30 & Solvent Evaporation & $1: 5$ \\
\hline SG1 & Celecoxib+PEG 6000 & Solvent Evaporation & $1: 1$ \\
\hline SG3 & Celecoxib+PEG 6000 & Solvent Evaporation & $1: 3$ \\
\hline SG5 & Celecoxib+PEG 6000 & Solvent Evaporation & $1: 5$ \\
\hline SU1 & Celecoxib+Urea & Solvent Evaporation & $1: 1$ \\
\hline SU5 & Celecoxib+Urea & Solvent Evaporation & $1: 5$ \\
\hline FG1 & Celecoxib+PEG 6000 & Fusion method & $1: 1$ \\
\hline FG3 & Celecoxib+PEG 6000 & Fusion method & $1: 3$ \\
\hline FG5 & Celecoxib+PEG 6000 & Fusion method & $1: 5$ \\
\hline FU1 & Celecoxib+Urea & Fusion method & $1: 1$ \\
\hline FU3 & Celecoxib+Urea & Fusion method & $1: 3$ \\
\hline FU5 & Celecoxib+Urea & Fusion method & $1: 5$ \\
\hline FM1 & Celecoxib+Mannitol & Fusion method & $1: 1$ \\
\hline FM5 & Celecoxib+Mannitol & Fusion method & $1: 5$ \\
\hline CP1 & Celecoxib+PVP K-30 & Coevaporation method & $1: 1$ \\
\hline $\mathrm{CP} 3$ & Celecoxib+PVP K-30 & Coevaporation method & $1: 3$ \\
\hline CP5 & Celecoxib+PVP K-30 & Coevaporation method & $1: 5$ \\
\hline CG1 & Celecoxib+PEG 6000 & Coevaporation method & $1: 1$ \\
\hline CG3 & Celecoxib+PEG 6000 & Coevaporation method & $1: 3$ \\
\hline CG5 & Celecoxib+PEG 6000 & Coevaporation method & $1: 5$ \\
\hline CU1 & Celecoxib+Urea & Coevaporation method & $1: 1$ \\
\hline CU3 & Celecoxib+Urea & Coevaporation method & $1: 3$ \\
\hline CU5 & Celecoxib+Urea & Coevaporation method & $1: 5$ \\
\hline CM1 & Celecoxib+Mannitol & Coevaporation method & $1: 1$ \\
\hline CM3 & Celecoxib+Mannitol & Coevaporation method & $1: 3$ \\
\hline CM5 & Celecoxib+Mannitol & Coevaporation method & $1: 5$ \\
\hline
\end{tabular}


packed as such in the powder XRD sample holder using a glass slide, loaded on the instrument. The instrument was run over a scan range of $2^{\circ}-50^{\circ}(2 \theta)[7]$.

\section{Preparation of celecoxib SD incorporated gels}

Preparation of gels

Gels were prepared using two polymers, Carbopol 971P, and HPMC $\mathrm{K} 4 \mathrm{M}$ as shown in Table 2 . The polymer and purified water were taken in a mortar and allow soaking for $24 \mathrm{~h}$. The SD was weighed and dissolved in water. It was slowly added to the soaked polymer and triturated well after each addition to get a homogenous dispersion of the drug in the gel. Propylene glycol was then added, and the trituration was continued.

Permeation enhancer - dimethyl sulfoxide (DMSO) was incorporated in different concentrations (1-30\%) into the gel.

Table 2: Preparation of gels containing SD CP5 in HPMC and Carbopol gels

\begin{tabular}{lll}
\hline Ingredients & HPMC gel (\%) & Carbopol gel (5) \\
\hline Celecoxib SD & 2 & 2 \\
HPMC K4M & 10 & - \\
Carbopol 971P & - & 1 \\
Propylene glycol & 10 & 10 \\
Triethanolamine & - & 0.5 \\
Purified water & q.s 100 & q.s 100 \\
\hline
\end{tabular}

Formulation of celecoxib gel with permeation enhancer - DMSO

Evaluation of celecoxib SD incorporated gels

Physical appearance and homogeneity

Gel formulation containing celecoxib was visually inspected for clarity, color, homogeneity, and the presence of particles and fibers [10].

\section{Determination of $\mathbf{p H}$}

Digital $\mathrm{pH}$ meter was used to check the $\mathrm{pH}$ of gels at room temperature. Initially, the $\mathrm{pH}$ meter was calibrated using standard buffers of $\mathrm{pH} 4$ and $\mathrm{pH}$ 9.2. Accurately, $2.5 \mathrm{~g}$ of gel was weighed and dispersed in $25 \mathrm{ml}$ purified water and $\mathrm{pH}$ of this dispersion was noted $[10,11]$.

The drug content of the prepared gels was carried out by dissolving accurately weighed quantity of gel equivalent to $10 \mathrm{mg}$ of the drug was dissolved in $10 \mathrm{ml}$ methanol. The volume was made up to $100 \mathrm{ml}$, and $5 \mathrm{ml}$ of the above solution was further diluted to $25 \mathrm{ml}$ with methanol. After suitable dilution absorbance of the solution was recorded using PerkinElmer Lambda 25 UV/VIS Spectrometer at $252.5 \mathrm{~nm}$.

\section{Spreadability}

Spreadability of gel formulations was determined by an apparatus suggested by Mortimer et al., which was suitably modified and used for the study. The spreadability was calculated using the formula

$$
\mathrm{S}=\mathrm{m} \cdot \mathrm{l} / \mathrm{t}
$$

Table 3: Preparation of gels containing SD and permeation enhancer - DMSO

\begin{tabular}{|c|c|c|c|c|c|c|c|}
\hline Ingredients & CPD1 (\%) & SPD1 (\%) & CPD2 (\%) & CPD3 (\%) & CPD4 (\%) & CPD5 (\%) & CPD6 (\%) \\
\hline Celecoxib SD & 2 & 2 & 2 & $2 \%$ & 2 & 2 & 2 \\
\hline HPMC K4M & 10 & 10 & 10 & 10 & 10 & 10 & 10 \\
\hline DMSO & 1 & 1 & 5 & 10 & 15 & 20 & 30 \\
\hline Propylene glycol & 10 & 10 & 10 & 10 & 10 & 10 & 10 \\
\hline Purified water & q. s 100 & q. s 100 & q. s 100 & q. s 100 & q. s 100 & q. s 100 & q. s 100 \\
\hline
\end{tabular}

Table 4: Drug content uniformity, percentage practical yield, and physical appearance of celecoxib SDs

\begin{tabular}{|c|c|c|c|c|}
\hline Formulation code & Drug content $(\%)$ & $\%$ practical yield & Color & Physical appearance \\
\hline SP1 & 96.60 & 94.75 & Off white & Powder (granular) \\
\hline SP3 & 96.18 & 90.62 & Off white & Powder (granular) \\
\hline SP5 & 95.98 & 88.00 & Off white & Powder (granular) \\
\hline SG1 & 98.25 & 89.50 & White & Fine Powder \\
\hline SG3 & 97.24 & 84.50 & White & Fine Powder \\
\hline SG5 & 96.82 & 88.56 & White & Fine Powder \\
\hline SU1 & 96.80 & 92.75 & White & Fine Powder \\
\hline SU5 & 95.70 & 93.00 & White & Fine Powder \\
\hline FG1 & 97.26 & 87.50 & White & Fine Powder \\
\hline FG3 & 96.54 & 92.25 & White & Fine Powder \\
\hline FG5 & 95.48 & 88.91 & White & Fine Powder \\
\hline FU1 & 96.10 & 90.62 & White & Fine Powder \\
\hline FU3 & 96.02 & 93.06 & White & Fine Powder \\
\hline FU5 & 95.12 & 92.34 & White & Fine Powder \\
\hline FM1 & 96.18 & 95.80 & White & Fine Powder \\
\hline FM5 & 95.32 & 94.00 & White & Fine Powder \\
\hline CP1 & 96.44 & 94.00 & White creamy & Fine Powder \\
\hline CP3 & 96.88 & 95.00 & White creamy & Fine Powder \\
\hline CP5 & 97.88 & 95.83 & White creamy & Fine Powder \\
\hline CG1 & 97.86 & 83.50 & White & Fine Powder \\
\hline CG3 & 97.62 & 84.50 & White & Fine Powder \\
\hline CG5 & 96.40 & 82.50 & White & Fine Powder \\
\hline CU1 & 96.02 & 90.87 & White & Fine Powder \\
\hline CU3 & 95.64 & 88.75 & White & Fine Powder \\
\hline CU5 & 2.67 & 88.58 & White & Fine Powder \\
\hline CM1 & 2.72 & 89.87 & White & Fine Powder \\
\hline CM3 & 2.71 & 84.76 & White & Fine Powder \\
\hline CM5 & 2.69 & 89.16 & White & Fine Powder \\
\hline
\end{tabular}


Where, $\mathrm{S}$ is spreadability, $\mathrm{m}$ is the weight tied to the upper slide, $\mathrm{l}$ is the length of the glass slide, and $t$ is the time taken [6].

\section{Extrudability}

The evaluation of gel formulation for extrudability was based on the quantity of gel (in percentage) extruded from the tube on the application of a certain load. The formulation under study was filled with a clean, lacquered aluminum collapsible $10 \mathrm{~g}$ tube with a nasal tip of $5 \mathrm{~mm}$ opening. It was placed in between two glass slides and was clamped. Extrudability was determined by weighing the amount of gels extruded through the tip when a constant load of $1 \mathrm{~kg}$ was placed on the slides and gels extruded was collected and weighed. The percentage of gel extruded was calculated and grades were allotted. (++: Good, +: fair) [12].

Table 5: Solubility measurements of celecoxib pure drug and its SDs

\begin{tabular}{ll}
\hline Formulation code & Solubility $(\boldsymbol{\mu g} / \mathbf{m l})$ \\
\hline Pure drug & $3.450 \pm 0.18$ \\
SU1 & $11.83 \pm 0.28$ \\
SP5 & $25.00 \pm 0.56$ \\
CP5 & $53.97 \pm 0.75$ \\
CM1 & $8.920 \pm 0.15$ \\
CU5 & $14.57 \pm 0.48$ \\
\hline
\end{tabular}

Mean \pm SD, $n=3$
In vitro diffusion study

The apparatus consists of a glass cylinder with both the ends open. A dialysis membrane was fixed to one end of the cylinder with the aid of an adhesive. Gels equivalent to $3.33 \mathrm{mg}$ of celecoxib were taken inside the cell (donor compartment), and the cell was immersed in a beaker containing $100 \mathrm{ml} 7.4 \mathrm{pH}$ phosphate buffer (receptor compartment). The medium in the compartment was agitated using a magnetic stirrer at a temperature $37^{\circ} \mathrm{C} \pm 1^{\circ} \mathrm{C}$. Aliquots $(5 \mathrm{ml})$ were withdrawn from the receptor compartment periodically at an interval of $30 \mathrm{~min}$ up to $6 \mathrm{~h}$ and replaced with $5 \mathrm{ml}$ of fresh buffer. After suitable dilution, the sample was analyzed using PerkinElmer Lambda 25 UV/VIS Spectrometer at $248 \mathrm{~nm}[13,17]$

Stability studies

The selected gel formulation was kept at two different temperature conditions, that is, $30 \pm 2^{\circ} \mathrm{C}$ and $5 \pm 2^{\circ} \mathrm{C}$ of accelerated stability testing for a period of 90 days, after which parameters such as color, $\mathrm{pH}$, spreadability, extrudability, drug content, and in vitro drug release were studied $[14,15]$

\section{RESULTS}

Drug content uniformity, percentage practical yield, and physical appearance of celecoxib SDs

Dissolution studies

Table 6: Physical parameters, drug content of the formulations

\begin{tabular}{|c|c|c|c|c|c|}
\hline Sr. No. & Formulation code & Physical appearance & Homogeneity & pH & $\%$ Drug content \\
\hline 1 & Carbopol gel & white translucent & ++ & 6.71 & $95.80 \pm 1.43$ \\
\hline 2 & HPMC gel & white translucent & ++ & 6.52 & $96.46 \pm 1.41$ \\
\hline 3 & CPD1 & white translucent & ++ & 6.92 & $96.85 \pm 1.38$ \\
\hline 4 & SPD1 & white translucent & ++ & 7.10 & $95.10 \pm 1.15$ \\
\hline 5 & CPD2 & white translucent & ++ & 6.34 & $96.49 \pm 1.43$ \\
\hline 6 & CPD3 & white translucent & ++ & 6.76 & $96.22 \pm 1.37$ \\
\hline 7 & CPD4 & white translucent & ++ & 7.04 & $96.51 \pm 1.31$ \\
\hline 9 & CPD6 & white translucent & ++ & 6.54 & $95.72 \pm 1.40$ \\
\hline
\end{tabular}

++: good; +: fair. mean $\pm S D, n=3$

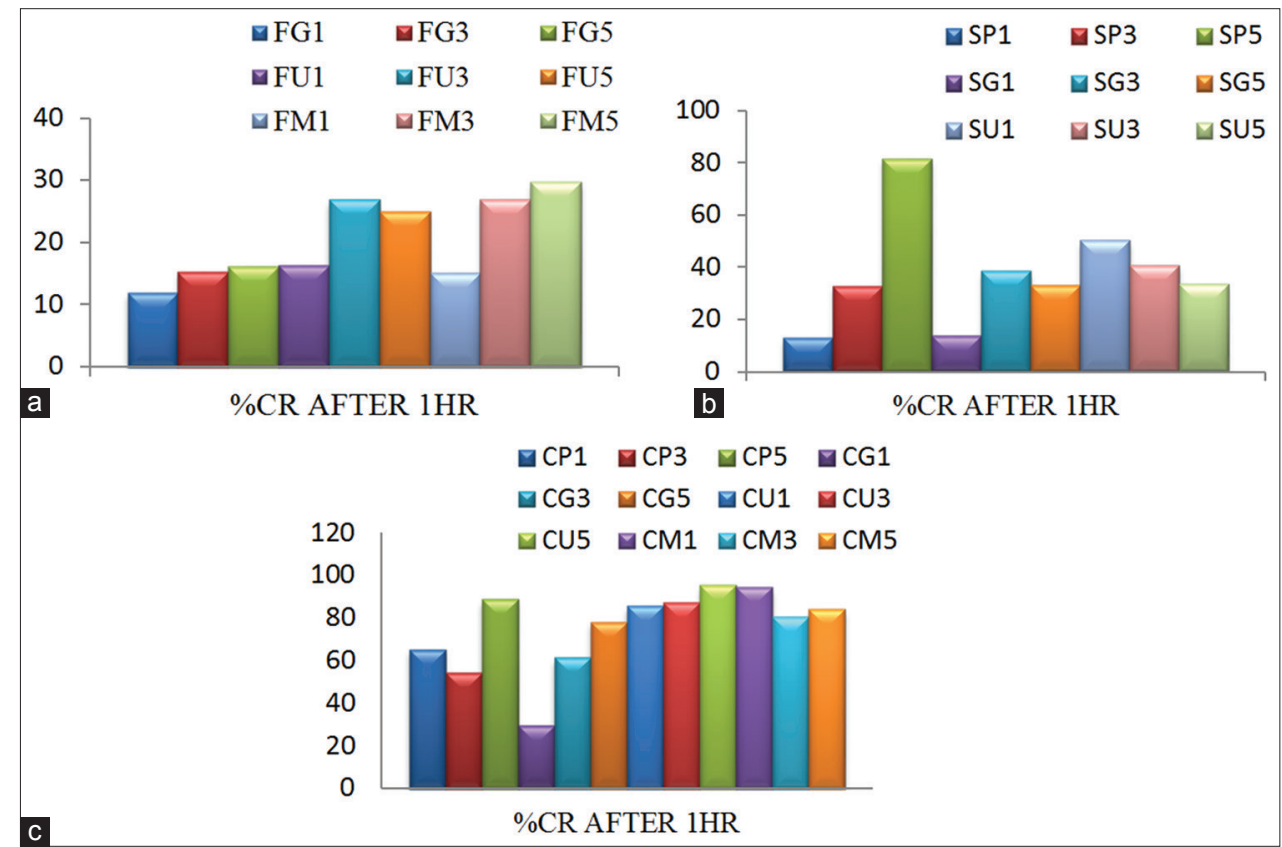

Fig. 1. Comparison of percentage cumulative drug release of celecoxib from solid dispersions prepared by (a) fusion method, (b) solvent evaporation method, and (c) coevaporation method, respectively 
Aqueous solubility studies DSC studies

XRD

SEM studies

Table 7: Rheological properties of the formulations

\begin{tabular}{llll}
\hline S. No. & Formulation code & Spreadability $(\mathrm{g}-\mathrm{cm} / \mathbf{s})$ & Extrudability \\
\hline 1 & Carbopol gel & 11.40 & ++ \\
2 & HPMC gel & 12.35 & ++ \\
3 & CPD1 & 13.40 & ++ \\
4 & SPD1 & 11.50 & + \\
5 & CPD2 & 14.90 & ++ \\
6 & CPD3 & 11.70 & ++ \\
7 & CPD4 & 12.60 & + \\
8 & CPD5 & 14.15 & ++ \\
9 & CPD6 & 13.80 & + \\
\hline++
\end{tabular}

++: Good; +: Fair
Evaluation of celecoxib solid dispersion incorporated gels Physical parameters and drug content of the formulations

Rheological properties of the formulations: Stability studies

\section{DISCUSSION}

Standard calibration curve of celecoxib

Standard plot of drug concentrations from 0 to $20 \mu \mathrm{g} / \mathrm{ml}$ was obtained. The straight line equations and regression coefficients obtained for methanol, $1 \%$ SLS in distilled water and buffer $\mathrm{pH} 7.4$ are $y=0.0055 x, R^{2}=0.999 ; y=0.056 x, R^{2}=0.999$; and $y=0.060 x, R^{2}=0.999$, respectively

\section{Percent practical yield}

The percentage practical yield of the prepared SDs was found to be in the range of $80.37-95.83 \%$. The maximum yield was found to be $95.83 \%$ in SD CP5 containing 1:5 ratio of celecoxib: PVP K-30.

Table 8: Stability studies data for optimized gel formulation

\begin{tabular}{llllll}
\hline Temperature & CPD5 gel & & & \\
\cline { 2 - 6 } & Drug content (\%) & In vitro diffusion study (\%) in $\mathbf{6} \mathbf{h}$ & $\mathbf{p H}$ & Spreadability & Extrudability \\
\hline $30 \pm 2^{\circ} \mathrm{C}$ & $96.94 \pm 1.43$ & 73.97 & 6.80 & 14.10 & ++ \\
$5 \pm 2^{\circ} \mathrm{C}$ & $97.01 \pm 1.38$ & 73.89 & 6.78 & 14.35 & ++ \\
\hline
\end{tabular}

mean $\pm S D, n=3$

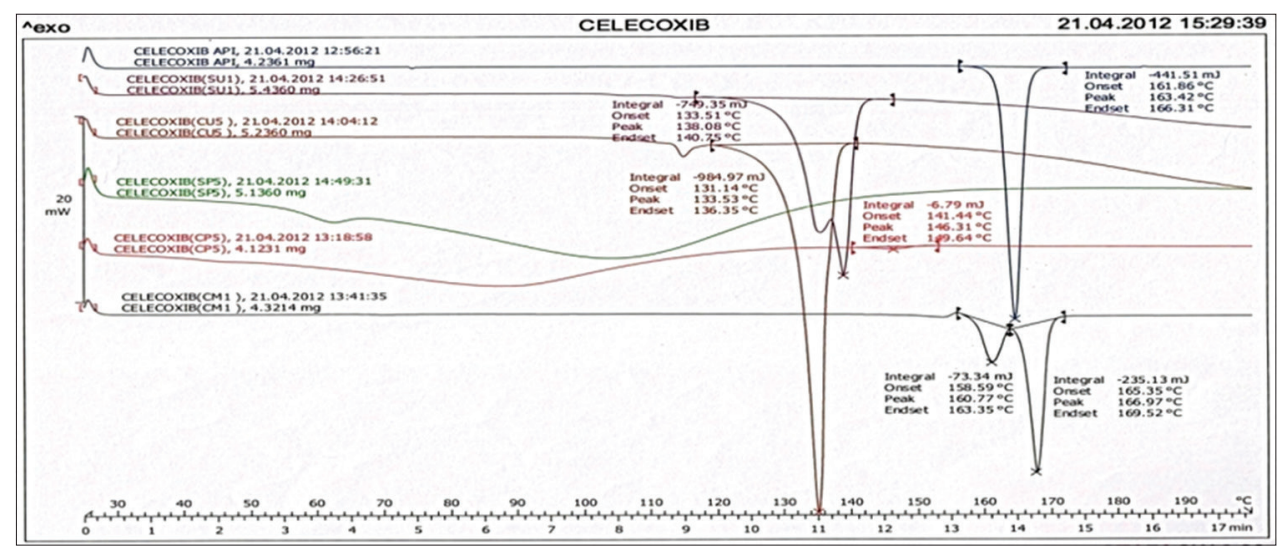

Fig. 2. Overlay of DSC thermogram of celecoxib and its solid dispersions

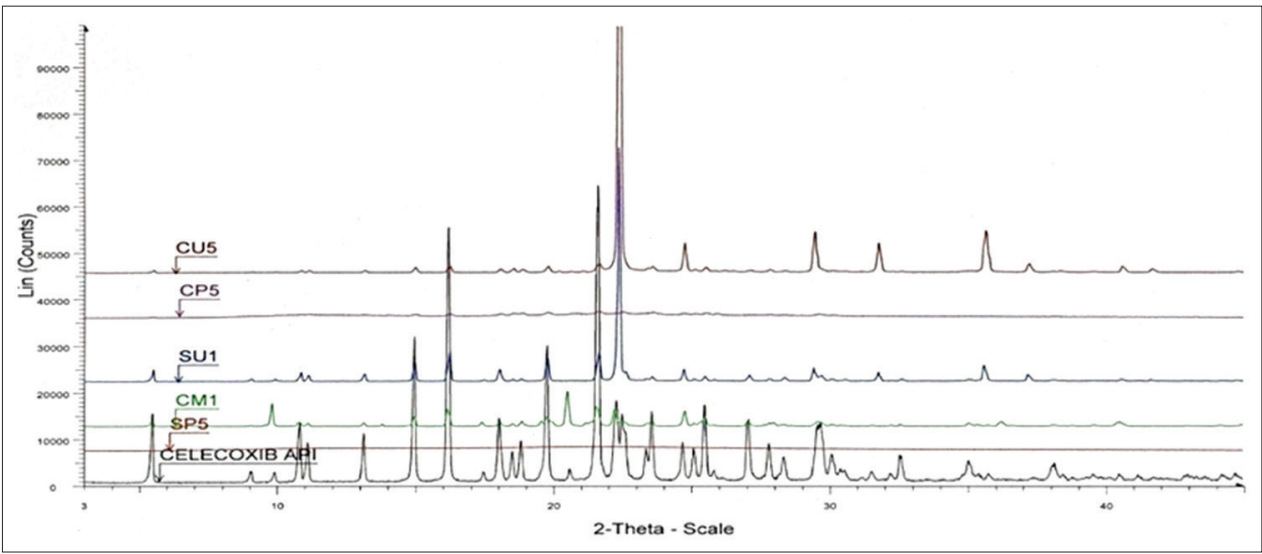

Fig. 3. Overlay of X-ray diffractogram of celecoxib and its solid dispersions 

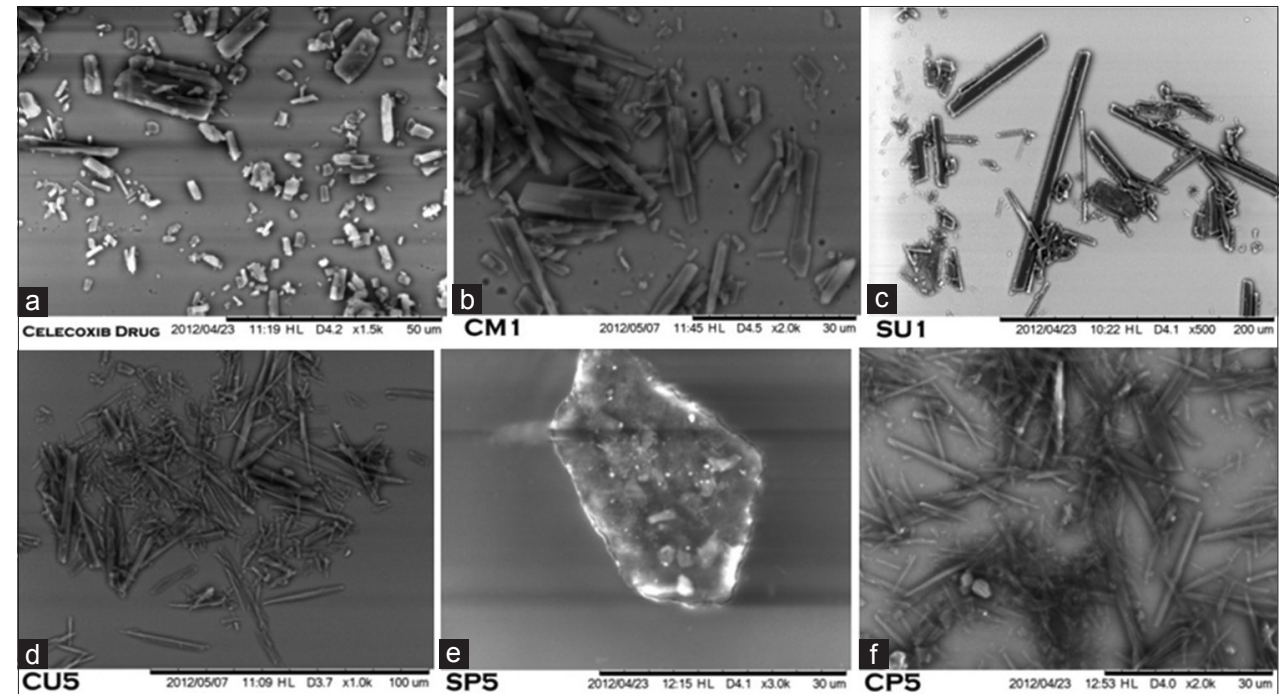

Fig. 4. SEM image of solid dispersion (a) pure drug celecoxib, (b) solid dispersion CM1, (c) SU1, (d) CU5, (e) SP5, and (f) CP5, respectively

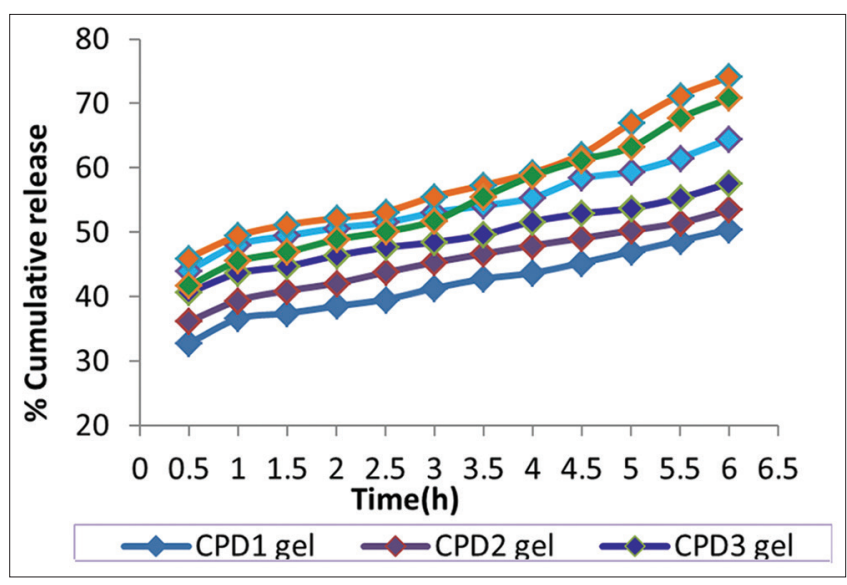

Fig. 5. In vitro drug release profile of celecoxib from formulated gels

Compatibility studies between celecoxib and excipients by IR spectroscopy

No interaction was observed when celecoxib and carriers/excipients mixture was tested.

\section{Drug content}

The drug content of the prepared SDs was found to be in the range of 95.12-97.88\% indicating that the application of the present methods for the preparation of SDs gave high content uniformity.

\section{Dissolution studies}

Release of Celecoxib from SDs was found to be faster than the pure drug itself. The reason for the poor dissolution of the pure drug could be poor wettability and agglomeration of particles. In the case of SDs probably the affinity of the hydrophilic inert carriers to the dissolution fluid facilitates rapid penetration into the particles, enhancing the dissolution process.

The order of efficiency of the methods used in the preparation of SDs is concluded as follows:

Coevaporation>solvent evaporation>fusion method

\section{Statistical analysis}

The in vitro drug release data of the selected SDs-CU5, CM1, CP5, SP5, and SU1 were treated to first-order, Higuchi diffusion plot, and Peppa's exponential plot. The $\mathrm{R}$ values for first-order plots were significantly higher as compared to zero-order plots which indicate that all the formulations best fitted in first-order kinetics and poorly fitted in zeroorder kinetics. The first-order plot was found to be fairly linear, indicating that the drug release followed first-order kinetics; with SD CP5 showing the highest $\mathrm{R}^{2}=0.993$. Similarly, the data were treated according to Higuchi's diffusion equation. The best fit with higher correlation was found with the Higuchi's equation for most of the formulations with the highest correlation coefficient $\left(\mathrm{R}^{2}=0.989\right)$ for SD CP5. The result indicated that all formulations exhibited diffusion mechanism in drug release. Further, the data were subjected to Peppa's model where the $\mathrm{R}$ value revealed that the Peppa's model best fitted in all dissolution profiles. Peppa's exponential plot gave slope values $<0.5$ for SDs CU5 (0.081), CM1 (0.138), and SU1 (0.425) indicating that the drug release followed Fick's law of diffusion, while the slope values for SDs SP5 (0.731) and CP5 $(0.637)$ were $>0.5$ indicating non-Fickian diffusion process.

\section{Aqueous solubility studies}

The solubility studies show a solubilizing effect of the carrier used which remarkably enhance the aqueous solubility of celecoxib. The efficiency of the carriers used in increasing the solubility of celecoxib thereby follows the order:

\section{PVP K-30>Urea>mannitol>PEG 6000}

\section{DSC studies}

The pure drug celecoxib subjected to DSC study started melting at $161.85^{\circ} \mathrm{C}$ and completed at $166.31^{\circ} \mathrm{C}$. The DSC thermogram of celecoxib showed a sharp endothermic peak at $163.42^{\circ} \mathrm{C}$ corresponding to its melting point, indicating its crystalline nature. It suggests the presence of a single compound in the pure form. Due to the absence of the endothermic peak of celecoxib in the SDs SP5, DSC studies reveal that celecoxib drug was no longer present in crystalline form and probably molecularly dispersed in amorphous form in the polymeric matrix of PVP K-30. The increase in the solubility of celecoxib could, therefore, be attributed to its conversion in the amorphous form.

\section{XRD}

The XRD studies show the conversion of the crystalline form of drug into amorphous form and hence, increases the solubility. These assumptions were found to be in full agreement with the results presented by the DSC studies.

\section{SEM studies}

In the SEM image of celecoxib, the drug crystals are seen as flat, bluntended tabular shaped crystals of various sizes. The SEM image of SD CP5 shows celecoxib drug particles uniformly dispersed throughout, wherein some of the drug crystals have lost their original tabular shape and are forming close aggregates. This indicates the presence of 
amorphous material and that there is also the formation of crystalline microaggregates of the drug and their considerable dispersions within the amorphous polymeric matrices of PVP K-30.

On the basis of all the above studies, increase in aqueous solubility being the main reason, SD CP5, and SP5, were selected for incorporation into gels using Carbopol 971P and HPMC as gelling agents.

SD CP5 was first used to prepare gels with Carbopol 971P and HPMC so as to arrive at the gelling agent giving better release of celecoxib from the gels. The in vitro diffusion study revealed that HPMC was more suitable to provide a better release of celecoxib with a percentage CR of $46.66 \%$ as compared to that of Carbopol with a percentage CR of $42.64 \%$ after $6 \mathrm{~h}$. Hence, HPMC was chosen to be used for the preparation of SP5 incorporated gel and to study the effect of incorporation of permeation enhancer - DMSO into the gels. The SPD1 gel containing a SD SP5 and 1\% DMSO was subjected to in vitro diffusion study and the in vitro percentage drug release of celecoxib was compared with that of CPD1 gel containing a SD CP5 and 1\% DMSO. The study showed that CPD1 gel gave better release of celecoxib with a percentage CR of $50.43 \%$ as compared to that of SPD1 gel with a percentage CR of $48.22 \%$ after $6 \mathrm{~h}$. Therefore, SD CP5 was chosen for study of the effect of incorporation of permeation enhancer - DMSO on the in vitro release of celecoxib from the gels. The concentration of DMSO used for the study was 1-30\%.

Gel formulations showed good extrudability and homogeneity. All the formulations were found to have good spreadability. The $\mathrm{pH}$ of all the formulations was between 6.34 and 7.10. This lies in the normal $\mathrm{pH}$ range of the skin. The drug content was in the range of $94.32-99.03 \%$.

Fig. 5 depicts the in vitro diffusion profile of celecoxib from gels containing a SD CP5 and different concentration of permeation enhancer DMSO over a period of $6 \mathrm{~h}$. It also depicts that $20 \%$ of dimethyl sulfoxide released a maximum of $74.13 \%$ of celecoxib within a period of 6 h. Further increase in DMSO concentration to 30\% showed no further increase in drug release. Among all gel formulations, the highest release of celecoxib was given by CPD5 gel, that is, $74.13 \%$. The pure drug and showed a cumulative percent release of $23.95 \%$.

\section{Statistical analysis}

The data obtained from the plots were subjected to linear regression analysis. The models that best fit the data were evaluated by the correlation coefficient (R). The $\mathrm{R}$ values for first-order plots were significantly lower as compared to zero-order plots which indicate that all the formulations best fitted in zero-order kinetics and poorly fitted in first-order kinetics. The zero-order plots were found to be fairly linear indicating the drug release, follows zero-order kinetics. The best fit with higher correlation was found with the Higuchi's equation for most of the formulations. The Higuchi diffusion plot was also linear, indicating that the drug release was diffusion controlled. Further, the data were subjected to Peppa's model where the R value revealed that the Peppa's model best fitted in all diffusion profiles. Peppa's exponential plot gave slope values $<0.5$ for all the gel formulations indicating that the drug release followed Fick's law of diffusion.

Based on the analysis and comparison of the results of all the evaluation tests of all gel formulations, an ideal optimized formulation was selected which gave satisfactory results for all evaluation tests which is a prerequisite for successful utilization of this dosage form. CPD5 gel was selected as the optimized formulation.

\section{Stability studies}

Stability studies revealed that formulated gel is stable.

\section{CONCLUSION}

The dissolution rate of celecoxib of SD was significantly higher than that of pure drug. SD prepared by coevaporation method showed a faster drug release than the dispersion prepared by solvent evaporation method followed by fusion method. The general trend indicated that there was an increase in dissolution rate for $\mathrm{SD}$ in the following order of PVP K-30 > urea > mannitol >PEG 6000. From all formulations, CPD5 gel, which was formulated using HPMC polymer and containing the SD CP5 with 20\% DMSO was found to be the best formulation.

\section{ACKNOWLEDGMENTS}

The authors are thankful to Unichem Laboratories Ltd., Geno Pharmaceuticals, Colorcon Asia Pvt. Ltd., for gift sample of drug and excipients.

\section{AUTHORS' CONTRIBUTIONS}

All authors have contributed equally.

\section{CONFLICTS OF INTEREST}

Declared none.

\section{REFERENCES}

1. Tripathi KD. Nonsteroidal Antiinflammatory Drugs and Antipyretics Analgesics, Essentials of Medical Pharmacology. $6^{\text {th }}$ ed. New Delhi: Jaypee Brothers Medical Publishers (P) Ltd.; 2008. p. 185-97.

2. Vyas J, Vyas P, Sawant K. Formulation and evaluation of topical niosomal gel of erythromycin. Int J Pharm Pharm Sci 2011;3:123-6.

3. Primo FT, Fröehlich PE. Celecoxib identification methods. Acta Farm Bonaerense 2005;24:421-5.

4. Chawla G, Gupta P, Thilagavathi R, Chakraborti AK, Bansal AK. Characterization of solid-state forms of celecoxib. Eur J Pharm Sci 2003;20:305-17.

5. Rao M, Mandage Y, Thanki K, Bhise S. Dissolution improvement of simvastatin by surface solid dispsersion technology. Dissol Technol 2010;2010;27-34.

6. Aejaz A, Azmail K, Sanaullah S, Mohsin A.A. Studies on aceclofenac solid dispersion incorporated gels: Development, characterization and in vitro evaluation. Int J Pharm pharm Sci 2010;2:111-5.

7. Lakshmi PK, Kumar MK, Sridharan A, Bhaskaran S. Formulation and evaluation of ibuprofen topical gel: A novel approach for penetration enhancement. Int J Appl Pharm 2011;3:25-30.

8. Patil SR, Kumar R, Patil MB, Paschapur MS, Rao VS. Enhancement of dissolution rate of aceclofenac by solid dispersion technique. Int J Pharma Tech Res 2009;1:1198-204

9. Muralimohanbabu GV, Gourishankar V, Himashankar K, Seshasayana A, Kishorekumar N, Ramanamurthy KV. Development of dissolution medium for a poorly water soluble drugs celecoxib. Indian J Pharm Sci 2002;64:588-91.

10. Sankar V, Chandrasekaran K, Durga S, Prasanth KG, Nilani P, Geetha $\mathrm{G}$, et al. Formulation and stability evaluation of diclofenac sodium ophthalmic gels. Indian J Pharm Sci 2005;67:473-6.

11. Panograha L, Ghosal SK, Pattanaik S, Mahasana L, Barik BB. Effect of permeation enhancer on the release and permeation kinetics of lincomycin hydrochloride gel formulation through mouse skin. Indian J Pharm Sci 2006;68:205-11

12. Gupta GD, Goud RS. Release rate of tenoxicam from acrypol gels. Indian Pharmt 2005;2005:69-75.

13. Brian KR, Walters KA, Walkinson AC. Investigation of skin permeation in vitro. In: Roberts MS, Walters KA, editors. Drugs and Pharmaceutical Sciences. Vol. 91. New York: Dermal Absorption and Toxicity Assessment; 1993. p. 164-5.

14. Daravath B, Tadikonda RR. Formulation and evaluation of meclizine hydrochloride fast dissolving tablets using solid dispersion method. Asian J Pharm Clin Res 2014;7:98-102.

15. Dua K, Ramanna MV, Sara UV, Himaja M, Garg V. Dissolution enhancement of aceclofenac through solid dispersions. Indian Pharm 2006;34:70-2

16. Anwar E, Harmita DR. Formulation and evaluation of gel and emulgel of chili extract (Capsicum frutescens L.) As topical dosage forms. Int J Pharm Pharm Sci 2014;6:13-6.

17. Jagdale S, Dangat $Y$, Kuchekar B. Improvement of dissolution rate of ramipril by solid dispersion technique and devlopement of buccal patch. Int J Pharm Pharm Sci 2012;4 Suppl 5:309-18.

18. Pandey A, Jagtap JV, Polshettiwar SA. Formulation and evaluation of in vitro antimicrobial activity of gel containing essential oils and effect of polymer on their antimicrobial activity. Int J Pharm Pharm Sci 2011;3:234-7. 